\title{
Três pesos, três medidas? Valor e cânone na série literária brasileira contemporânea
}

\author{
Triple Standards: Value and Canon in Brazilian Contemporary Literature \\ Ivete Lara Camargos Walty \\ Pontifícia Universidade Católica de Minas Gerais/Cnpq/FAPEMIG - Belo Horizonte - Minas Gerais - Brasil
}

$\diamond$

\begin{abstract}
Resumo: Reflexão sobre tendências da narrativa brasileira contemporânea por meio da análise de três antologias publicadas a partir do ano 2005: Literatura marginal, talentos da escrita periférica, de Ferréz (2005), Granta: os melhores jovens escritores brasileiros, de Roberto Feith e Marcelo Ferroni (2012), e Geração subzero: 20 autores congelados pela crítica, mas adorados pelos leitores, de Felipe Pena (2012), com o objetivo de discutir os critérios de valor que as subsidiam. Levando em consideração aspectos estéticos, políticos e éticos, tal análise levará, pois, em conta a relação entre valor e cânone que rege a elaboração, circulação e recepção das antologias, em seus lugares na cena literária brasileira.
\end{abstract}

Palavras-chave: Antologias; Cânone; Valor; Aspectos estéticos, éticos e políticos.

\begin{abstract}
Reflection upon the tendencies for Brazilian contemporary writing through three anthologies published since 2005: Literatura marginal, talentos da escrita periférica, by Ferréz (2005), Granta: os melhores jovens escritores brasileiros, by Roberto Feith and Marcelo Ferroni (2012), and Geração subzero: 20 autores congelados pela crítica, mas adorados pelos leitores, by Felipe Pena (2012), aiming to discuss the value criteria adopted by the editors. Considering aesthetical, political and ethical aspects, this analysis will take into account the relationship between value and canon which defines the elaboration, circulation and reception of anthologies in their places inside Brazilian literary scene.
\end{abstract}

Keywords: Anthologies; Canon; Value; Aesthetical; Ethical and political aspects.

Neste artigo abordam-se as antologias Literatura marginal, talentos da escrita periférica, de Ferréz (2005), Granta: os melhores jovens escritores brasileiros, de Roberto Feith e Marcelo Ferroni (2012), e Geração subzero: 20 autores congelados pela crítica, mas adorados pelos leitores, de Felipe Pena (2012), com o objetivo de discutir os critérios de valor que as subsidiam.

Nos títulos das três antologias citadas acima podem ser observados três mapas desenhados sob diferentes escalas. $\mathrm{Na}$ primeira, publicada em 2005, um autor oriundo da favela de Capão Redondo, que já publicara os romances Fortaleza da desilusão (1997), Capão pecado (1999) e Manual prático do ódio (2003), reúne textos de autores cuja enunciação é marcada pelo lugar da exclusão social. A segunda traz o selo da internacionalidade e da tradição, conferindo-se o status da Universidade de Cambridge e da tradicional origem em 1889. E a terceira, marcando seu lugar de oposição à crítica literária, reivindica o direito de portar o rótulo de entretenimento.
No prefácio intitulado "Terrorismo literário", o organizador da primeira antologia aqui citada, Ferréz, evoca a capoeira como atividade ligada aos negros, escravos ou libertos, proibida aos seus praticantes pelo governo da época, e se propõe usar como nova arma a palavra de um determinado segmento da população cujo lugar pouco teria mudado na sociedade contemporânea. Valendo-se, então, de uma série de advérbios de negação, marca seu lugar de enunciação com o signo da resistência:

A capoeira não vem mais, agora reagimos com a palavra, porque pouca coisa mudou, principalmente para nós.

Não somos movimento, não somos os novos, não somos nada, nem pobres, porque pobre, segundo os poetas da rua, é quem não tem as coisas. (FERRÉZ, 2005 , p. 9 - grifos acrescentados)

Uma identidade enunciativa se constrói com o uso do pronome nós, que traz as marcas de um grupo, de um 
tempo/espaço e de uma história. A contraposição entre esse enunciador e seus enunciatários faz parte dessa estratégia de atacar para se defender. Um diálogo em sentido estrito se intercala:

Cala a boca, negro e pobre aqui não tem vez! Cala a boca!

Cala a boca uma porra, agora a gente fala, a gente canta, e na moral agora a gente escreve. (FERRÉZ, 2005, p. 9)

O uso de imperativo reproduz cenas de intimidação em que os lugares do opressor e do oprimido estão bem delineados, enquanto o emprego da forma "a gente" reforça o espaço de um sujeito coletivo em construção. Esse sujeito plural se concede o direito da palavra oral ou escrita, na busca de sair do lugar de objeto: "Não somos o retrato, pelo contrário, mudamos o foco e tiramos nós mesmos a nossa foto.” (FERRÉZ, 2005, p. 9).

$\mathrm{Na}$ assunção da palavra literária busca-se um lugar na polis, declarando a oposição a uma força políticoideológica. O uso do não é reiterado na recusa do que seria a reprodução do sistema de escravização do outro comum ao capitalismo:

O sonho não é seguir o padrão, não é ser empregado que virou patrão, não, isso não, aqui ninguém quer humilhar, pagar migalhas nem pensar, nós sabemos a dor por recebê-las. (FERRÉZ, 2005, p. 9)

O ritmo sincopado do rap e a rima em -ão reforçam o aspecto capoeira do texto em seu hibridismo performático: arte, dança, música, luta. Essa luta determina o adversário: "somos contra sua opinião, não viveremos ou morreremos se não tivermos o selo da aceitação" (FERRÉZ, 2005, p. 9). A oposição entre "literatura boa/feita com caneta de ouro e literatura ruim/escrita com carvão" refere-se a autores de quem se recusaria agora o aval. Observese que a questão do valor e do cânone em sua relação com os conceitos de estética, ética e política, além do universo do mercado, aí se instala de forma candente. A rua quer invadir os espaços consagrados não só da arte, mas também da lei; questionam-se as vozes que proclamam os "direitos iguais" e a crença de que "todos são livres" enquanto as relações de poder mantêm os lugares estabelecidos desde os tempos da casa-grande e da senzala.

Outra contraposição se estabelece quando o enunciador repele as práticas criminosas pelas quais se visa obter o que o outro tem: o roubo, o tráfico, o assassinato. A alusão ao império do consumo instigado pela publicidade se faz também pelo uso do imperativo na reprodução da voz do outro:
O jogo é objetivo, compre, ostente, e tenha minutos de felicidade, seja igual ao melhor, use o que ele usa.

Mas nós não precisamos disso, isso traz morte, dor, cadeia, mães sem filhos, lágrimas demais no rio de sangue da periferia. (FERRÉZ, 2005, p. 10)

O universo do nós, mesmo em sua recusa, contém o germe da violência, que é de seus agentes físicos, mas também da sociedade como um todo. A arte viria como possibilidade de saída do círculo da violência. Nesse sentido, vale lembrar Hannah Arendt, quando mostra a palavra como chave da vida em sociedade já na polis grega. É então que ligando ação política e palavra, afirma: "somente a pura violência é muda" (ARENDT, 2005, p. 35).

O texto de Ferréz, em seu jogo de contraposições, apela por um ouvinte e o repele: "não precisamos de sua legitimação, porque não batemos na porta para alguém abrir, nós arrombamos a porta e entramos." (FERRÉZ, 2005 , p. 10). A palavra incorpora de alguma forma a violência, como já se nota desde o título com o uso do termo terrorismo. Esse terrorismo verbal constrói-se como um manifesto. É bom lembrar que o gênero manifesto fazse por excelência o lugar da palavra em ação, como se pode constatar já em sua etimologia:

\begin{abstract}
No sentido primeiro que a palavra "manifesto" evoca está presente a ideia de "coisa ou declaração de razões tornadas públicas", envolvendo um programa político, estético ou religioso. Etimologicamente o vocábulo vem do latim manifestus: manus significando posto ao alcance da mão, apanhado em flagrante (Cf. TORRINHA. 1942), e o adjetivo festus com o sentido de alegre, festivo, mas tendo também o sentido de público. (CURY; WALTY, 2009, p. 225)
\end{abstract}

Manifestar-se significa também tornar-se visível e a maneira para que isso se concretize no meio adverso é, para Ferréz, negar a negação:

Estamos na rua, loco, estamos na favela, no campo,
no bar, nos viadutos, e somos marginais mas antes
somos literatura, e isso vocês podem negar, podem
fechar os olhos, virar as costas, mas, como já disse,
continuaremos aqui, assim como o muro social
invisível que divide este país. (FERRÉZ, 2005, p. 10)

Quem se abriga sob o pronome vocês? Aqueles que pertencem às camadas dominantes? Aqueles que não querem ver os problemas sociais? Aqueles que recusam aos enunciadores o direito de dizer eu? Entre estes seguramente estão os que também recusam a classificação de literatura a textos como os que se agrupam na antologia em foco. O eu que fala em nome do nós, como fica mais evidente na frase "como já disse", coloca-se em uma 
trincheira de guerra e evoca seus adversários contrapondose a seus valores e padrões. Contrapondo-se? Podemos nos perguntar em que medida tal batalha se institui sem misturar modelos e padrões, inclusive o da afirmação da autenticidade, o da importância de se publicar em livros conferindo-se um status e o de receber prêmios. Depois de explicar as razões de um livro e de contar suas origens com a publicação de 3 números da revista Caros amigos dedicados à literatura marginal, Ferréz proclama: "Ganhamos até prêmios, como o da Apca (Academia Paulista de Críticos de Arte), 'melhor projeto especial do ano"” (FERRÉZ, 2005, p. 12).

O que se pode verificar aqui é que o embate é também retórico, pois essa trincheira aí erguida é mais híbrida e complexa do que se declara. Isso porque não se debulham as palavras como se debulha uma espiga de milho, pois estas de organizam em redes, fazendo cruzar trajetórias e histórias. Veja-se, por exemplo, a referência ao ensaio "Kafka, por uma literatura menor", de Deleuze e Guatari (1977), que acaba por introduzir no texto outras linhas: a de outras culturas e de outras línguas, de relações de poder e tentativas de afirmação de lugares de enunciação desconsiderados, entre outras.

$\mathrm{A}$ oposição maior $\mathrm{X}$ menor, maioria $\mathrm{X}$ minorias a que se refere Ferréz é reproduzida no mercado das artes, na crítica cultural, nos congressos universitários. $\mathrm{O}$ autor antevê uma crítica à dicotomia proposta em seu prefácio quando diz:

Cansei de ouvir:

- Mas o que cês tão fazendo é separar a literatura, a do gueto e a do centro.

O barato já está separado há muito tempo, só que do lado de cá ninguém deu um grito, ninguém chegou com a nossa parte, foi feito todo um mundo de teses e de estudos do lado de lá, e do cá mal terminamos o ensino dito básico. (FERRÉZ, 2005, p. 13)

Em um movimento de afirmação pela negação, como nos primeiros movimentos feministas, a disposição para o confronto é inevitável, o que não impede que o leitor perceba as contradições entre o afastamento e o apelo. Por isso mesmo, o prefácio estabelece diferenças entre seus possíveis leitores: "Boa leitura, e muita paz se você merecê-la, senão, bem-vindo à guerra." (FERRÉZ, 2005, p. 13).

No "mundo dos estudos", em que se incluem os autores de artigos como este, a polêmica é acirrada e suscita perguntas que não aceitam que livros como o de Ferréz sejam objeto de estudos acadêmicos: _ Com que critérios julgar textos sem qualidade estética? Se a literatura prima pela qualidade como levar para a sala de aula esse tipo de texto? E a norma culta da língua assim tão vilipendiada?
Essas e outras questões colocadas no mundo acadêmico e cultural apontam para necessidade de se verificar se uma única medida pode dar conta de pesos tão diferentes. Antonio Candido já demonstrara que um dos elementos mais importantes a ser considerado no momento de formação da literatura brasileira é justamente o grande contingente de iletrados ${ }^{1}$ que permeava o público recebedor das obras, que não seria, por isso mesmo, necessariamente um público leitor. Candido considera que esse público de auditores acabou por interferir no estilo da escrita das obras publicadas para atingir, através de recursos retóricos eficientes, aqueles que não liam.

Evidenciando depois a mudança da relação entre o público, em desenvolvimento na época do Modernismo, e o escritor, então com mais possibilidade de publicar seus textos, Candido chama a atenção para o fato de que esse novo público, "à medida que crescia, ia sendo rapidamente conquistado pelo grande desenvolvimento dos novos meios de comunicação". E continua:

\begin{abstract}
Viu-se então que, no momento em que a literatura brasileira conseguia forjar uma certa tradição literária, criar um certo sistema expressivo que a ligava ao passado e abria caminhos para o futuro, - neste momento as tradições literárias começavam a não mais funcionar como estimulante. Com efeito, as formas escritas de expressão entravam em relativa crise, ante a concorrência de meios expressivos novos, ou novamente reequipados, para nós, - como o rádio, o cinema, o teatro atual, as histórias em quadrinhos (CANDIDO, 1976, p. 137)
\end{abstract}

No ensaio "Literatura e subdesenvolvimento" (1979, 1986), o mesmo crítico retoma o assunto e mantém a defesa da alfabetização fonética, que ele julga fortemente ameaçada pela cultura de massa. Silviano Santiago, comentando tal postura, preconiza o alargamento dos conceitos de alfabetização e leitura, para que possam acolher a recepção de outras formas culturais. Diz Santiago:

Em outras palavras: um homem de boa vontade hoje, um cidadão, mesmo analfabeto, tem uma quantidade de informação que ultrapassa, e muito, a informação que tinha um homem de boa vontade, um cidadão, mesmo alfabetizado, há meio século. O grave problema é o de saber como transformar a quantidade de informação em conhecimento, como conduzir um cidadão a incorporá-la qualitativamente para que dela se possa valer na sua compreensão da sociedade e do mundo em que vive. Já sabemos que, nos países periféricos, não será pela simples e espinhosa alfabetização fonética. (SANTIAGO, 2004, p. 129).

\footnotetext{
1 "Os analfabetos eram no Brasil, em 1890, cerca de 84\%; em 1920 passaram a 75\%; em 1940 eram 57\%. (CANDIDO, 1976, p. 137).
} 
Este quadro evidencia movimentos entre grupos sociais, entre diferentes mídias e entre diferentes expressões culturais, e, por isso mesmo, compreende o conceito de espaço público, tomado como um lugar de interseção entre o Estado e a sociedade civil.

Se se considera, com Habermas (2003), o papel da literatura na formação do espaço público burguês, podese constatar o alijamento dos não-letrados desse espaço. Se isso já ocorria na França, Inglaterra e Alemanha, países utilizados pelo autor, para o delineamento daquilo que seria visto como o espaço público burguês, o que ocorreu e ainda ocorre no Brasil, cujas dificuldades sociais complicam a situação, pode ser deduzido com mais facilidade.

Viu-se então que o problema posto pelo prefaciador/ organizador da obra Literatura marginal não é novo, assim como as relações de poder que ele descreve. Um elemento novo nessa equação seria a disposição desse segmento social, até então alijado, de adentrar o mercado editorial bem como a correspondência de algumas editoras a esse anseio. Não se discutirão aqui as inúmeras causas dessa relação de produção, circulação e consumo, antes vale assinalar um processo que se impõe confirmando a afirmação de Ferréz: "Mas estamos na área, e já somos vários".

Mesmo que se relativizem os conceitos de verdade e autenticidade de um grupo e de uma literatura, que acabam por também, de forma simplista, excluir do conjunto outros segmentos, há que se considerar essas linguagens em busca de identidade e afirmação. Não isoladamente, mas em diálogo com outras linguagens, inclusive aquela atacada como a "dos inimigos".

Se a rua é espaço público por excelência, ela pode acolher a multiplicidade possibilitando a troca e a interação. Perceber a literatura dos cantos e das quebradas não implica em isolá-la em guetos, repetindo o movimento que se quer extirpar. Antes há que se delinear novos percursos e configurações de mapas em movimento.

Em uma das constelações possíveis insira-se nessa reflexão uma outra antologia sem aparentemente um selo político-ideológico, a Granta em português. Como já se referiu, na introdução, escrita por Roberto Feith e Marcelo Ferroni, confere-se à publicação um teor de consagração internacional estendido aos vinte jovens autores selecionados, "que através de seu trabalho contribuem para mudar o panorama das letras no país". (GRANTA, 2012, p. 5) Afiança-se ainda que os textos dos autores dados como "os melhores jovens escritores brasileiros" serão divulgados também pela Granta em inglês e em espanhol, o que lhe assegurará um público de "oitenta mil aficionados da literatura na América Latina, Espanha, Estados Unidos e Reino Unido, alcance inédito para estes jovens brasileiros." (GRANTA, 2012, p. 5).
Outro aval da publicação e de seus autores são os prêmios até antão recebidos por alguns deles, como Michel Laub, Tatiana Salem Levy e Daniel Galera, bem como seu traço comum que não estaria nos temas, mas "no vigor e apuro estilístico - o acerto nos detalhes, a busca por uma linguagem coesa, o desenvolvimento cuidadoso de personagens." (GRANTA, 2012, p. 6).

Depois de listar os autores e resumir seus contos, reitera-se a importância da revista para o estabelecimento do cânone nacional e internacional, em um movimento circular; a revista antecipa nomes que vão ser incorporados à cena literária, assim como seu anterior pertencimento a essa cena já lhes abre caminho para serem selecionados. A citação de nomes é outro mecanismo de consagração dos escritores e da revista que veicula seus textos, assim como os nomes dos integrantes do júri que selecionou entre 247 inscritos os 20 melhores. Verifica-se com os nomes de Beatriz Bracher, Cristovão Tezza, Samuel Titan, Manuel da Costa Pinto e Ítalo Moriconi, além do norte-americano Benjamin Moser, o aval de profissionais reconhecidos; qualquer leitor que se interesse por literatura e leia eventualmente os jornais Folha de São Paulo ou Estado de São Paulo reconhecerá a maioria dos nomeados.

Nos mecanismos descritos vêem-se critérios de canonização dos escritores e se confere o lugar que a literatura brasileira vem conquistando no cenário mundial. Dizem os autores:

O Brasil vive um momento especial na literatura. Nas últimas décadas, poucos autores foram publicados e reconhecidos fora do país. Os motivos eram diversos: de uma suposta literatura difícil às barreiras da língua. (GRANTA, 2012, p. 9)

A gradual inserção da literatura brasileira no mercado se dá com a ajuda de uma rede de tradutores, de agentes editoriais, bem como da presença em feiras internacionais como a de Frankfurt, que escolheu o país para ser homenageado em sua edição de 2013. Observe-se que o processo da entrada do Brasil no cenário internacional não difere muito daquele que marca a entrada da chamada literatura marginal na cena brasileira. Afinal é sempre a questão da marginalização a determinar lugares e/ou deslocamentos. O que muda são os agentes envolvidos, ora como os julgados, ora como os julgadores. Afinal, à barreira da língua portuguesa no espaço mundial não corresponderia, em alguma medida, aquela da norma culta que impediria a inserção dos autores como os da antologia do Ferréz no espaço cultural brasileiro?

Veja-se, por exemplo, que no Caderno Ilustrada, da edição de 16 de julho de 2012 da Folha de S. Paulo, a matéria intitulada "Os eleitos", com direito a fotos da maioria dos autores, registra o "debate sobre critérios e marcas para definir gerações literárias” (E1). 
Nesse debate encontra-se mais um ingrediente a complicar o processo dos estatutos da literatura, o referente à mídia e ao entretenimento. Como mostra a matéria jornalística, "o escritor Felipe Pena lançou na FLIP seu Geração subzero (...), cuja orelha critica a seleção da revista britânica":

A 'Granta teve a pretensão de apresentar os 20 melhores autores. Mas que critérios definem os melhores? E quem define esses critérios? Figurinhas carimbadas pela 'mídia especializada' e referendadas pelas panelas literárias levam vantagem. $(\mathrm{E} 1)^{2}$

Em sua crítica, Filipe Pena cita ironicamente mais um critério de valorização:

A Granta se leva a sério demais. Quando um editor disse que aqueles autores vão construir o mapa da literatura brasileira, falei para meu sobrinho de 5 anos: 'Melhor começar a ler todos, esses caras vão cair no vestibular!' (E1)

A universidade aparece como espaço de canonização, reafirmando o antigo sentido de clássico como aquele que é lido em classe e, além disso, sabe-se que quatorze dos vinte selecionados "fizeram oficinas literárias ou estudam literatura na universidade", o que leva a matéria do jornal a concluir que "a dedicação ao ofício distingue essa geração das que as precederam, cheias de funcionários públicos ou profissionais liberais.” (E1). Outro fator mencionado é a maior facilidade de publicação em editoras artesanais e mesmo nos grandes grupos editoriais. Vozes dissonantes de críticos brasileiros também apontam aspectos negativos ou positivos da publicação em pauta, como a de Alcir Pécora, que a vê como simples produto de mercado ou a de Nelson de Oliveira, que acentua a importância de publicar antologias. É bom lembrar que ele mesmo foi alvo de críticas com a publicação das antologias Geração noventa: manuscritos de computador, Geração noventa: os transgressores, e Geração zero, zero, que, por sinal são citadas em outra matéria do mesmo jornal, dessa feita no Caderno Ilustríssima no dia 2 de setembro de 2012, em que se tenta, em viés mais analítico, discorrer sobre a temática e o estilo dos contos, bem como sobre o lugar social dos autores da Revista Granta. Estabelecendo um paralelo entre Granta e mais 2 antologias - Os cem melhores contos brasileiros do século ${ }^{3}$ (MORICONI, 2000) -, e Geração 90 - manuscritos de computador (OLIVEIRA, 2001), Luís Augusto Fischer constata que "O grupo dos escritores da "Granta" é o mais metropolitano, como $90 \%$ de nascidos em capitais, enquanto no "Geração 90" há mais gente nascida no interior (41\%). Além disso, a

\footnotetext{
Seria interessante conhecer os nomes daqueles que, candidatando-se integrar a antologia, foram rejeitados.

3 Aqui considerada a seção "Anos 90: estranhos e intrusos".
}

despeito de uma razoável distribuição entre os estados da federação, a maioria é radicada nas regiões sul e sudeste. Mais do que isso, o articulista observa que os selecionados de Granta "nasceram entre as classes confortáveis e vivem como escritores, editores, colunistas, críticos, tradutores, roteiristas - em suma, gente do meio letrado, em larguíssima maioria (Ilustríssima, p. 6). Outro traço em relevo, antes apontado por Marcelo Coelho, é a mudança do cenário sócio-cultural também das personagens. Diz o autor, comentando a grande repercussão do lançamento da Granta:

Aqui na Folha, Marcelo Coelho percebeu novidades num relance: saíram de cena os pobres e os desajustados, assim como a prosa regionalista viciosa, dando lugar a personagens requintados, vivendo experiências na Europa. (Ilustríssima, p. 6)

Em vista dessa mudança o mundo das ruas e das favelas cede espaço à internacionalização do cenário, marcada tanto pelo trânsito das personagens e dos próprios autores, como pelo registro culto da língua e das referências livrescas.

Mas a 'Granta' se afasta de outra curva regular: nela, $90 \%$ dos personagens relevantes se encontram nas classes confortáveis (da classe média para cima, não passa por apertos significativos de vida). $\mathrm{Na}$ antologia de Moriconi, a divisão era bem outra: $59 \%$ de gente confortável; na antologia de Nelson de Oliveira, apenas e tão somente $35 \%$, a maioria sendo gente das classes carentes.

Interessante perguntar, pois, se essa mudança de cenário, se daria em uma lógica de substituição, ou de convivência de tendências. Afinal não seria sobre isso que escreve Silviano Santiago em seu ensaio "Uma literatura anfíbia"? Aí o autor discorre sobre o que seria um vazio temático referente "à parca dramatização na literatura dos problemas dominantes na classe média, que fica espremida entre os dois extremos da sociedade" (SANTIAGO, 2004, p. 67). Levando em consideração os critérios de seleção de leitura do estrangeiro, Santiago propõe que esse tipo de leitor não aceitaria o caráter anfíbio de uma literatura que mistura arte e política. É então que justifica a permanência desse tipo de arte:

A contaminação é antes a forma literária pela qual a lucidez do criador se afirma duplamente. A forma literária anfíbia requer a lucidez do criador e também a do leitor, ambos impregnados pela condição precária de cidadãos numa nação dominada pela injustiça. (SANTIAGO, 2004, p. 69)

A questão aí enfocada envolve estética, política e ética. Diante disso pode-se perguntar se a seleção de Granta em 
sua abertura para outros países estaria deixando de lado tal estágio de contaminação na busca de conquista de novos leitores. Não sem antes apontar que essa é uma tendência ligada ao movimento de globalização e borramento das fronteiras nacionais, interroga-se se não seria essa uma das causas da abertura do mercado editorial brasileiro.

Em lugar do movimento dado como estética da fome (ROCHA, 1965) ou até "cosmética da fome" (BENTES, 2001), marcado pelo exotismo que atravessaria a história da literatura brasileira, surgiria uma corrente depurada das mazelas sociais brasileiras? Seria esse o modelo em que a literatura cria seu próprio referente, voltando-se para si mesma?

A resposta afirmativa a essas questões indiciariam uma visão excludente que dá à noção de rede um grau de positividade que pode levar a outra forma de etnocentrismo. Nesse sentido, vale recorrer à Doreen Massey quando vê a modernidade como um movimento nivelador, em que uma história ou uma temporalidade quer se impor a todas as outras. Afirma a autora:

O que se desenvolveu dentro do projeto de modernidade, em outras palavras, foi o estabelecimento e a (tentativa de) universalização de uma maneira de imaginar o espaço (e a relação sociedade/espaço) que afirmou o constrangimento material de certas formas de organizar o espaço e a relação entre sociedade e espaço. E que ainda permanece hoje em dia. (MASSEY, 2008, p. 103)

"E ainda permanece hoje em dia". Essa frase nos interessa na medida em que considerar pela lógica da substituição que uma antologia com seus critérios de seleção, com seu modelo estético, apaga outras ou as invalida, é fragmentar o espaço fechando o trânsito a autores e personagens. Volta a analogia com a colonização: o Brasil e as forças externas; os grupos marginalizados e as forças internas.

Para embaralhar mais os nós dessa rede, importa analisar a proposta da terceira antologia objeto dessa reflexão: Geração subzero. No subtítulo, "20 autores congelados pela crítica, mas adorados pelos leitores", já se instala um antagonismo, marcado pela adversativa "mas".

No início da introdução escrita por ele, o organizador Felipe Pena retoma palavras utilizadas por ele mesmo em uma entrevista concedida a um jornal carioca em 2008:

Boa parte da literatura brasileira contemporânea presta um desserviço à leitura. Os autores não estão preocupados com os leitores, mas apenas com a satisfação da vaidade intelectual. Escrevem para si mesmos e para um ínfimo público letrado e pretensamente erudito, baseando as narrativas em jogos de linguagem que têm como objetivo demonstrar uma suposta genialidade pessoal. Acreditam que são a reencarnação de James Joyce e fazem parte de uma estirpe iluminada. Por isso, consideram um desrespeito ao próprio currículo elaborar enredos ágeis, escritos com simplicidade e fluência. (PENA, 2012, p. 9)

Desculpando-se por ter sido "Injusto e deselegante" com autores brasileiros que não mereceriam tal crítica, o autor confessa que suas palavras eram uma estratégia para entabular ou alimentar a discussão sobre os critérios utilizados pela crítica acadêmica, que ele reputa anacrônicos porque apegados "aos formalistas russos do início do século passado" (PENA, 2012, p. 10). Não sem deixar de se incluir no conjunto, ele critica "os doutores universitários" que prejudicariam a formação de um público leitor. Vale-se ainda das palavras de João Ximenes Braga em resposta a uma crítica da Professora Beatriz Resende para reiterar a ideia de que no mundo literário não se aceita a diversidade e se elege um único cânone como camisa de força a que deve se sujeitar a produção literária.

Defendendo a narração de histórias em detrimento da experimentação lingüística e atribuindo à crítica acadêmica a defesa do texto hermético de difícil leitura, Pena postula o conceito de entretenimento como parte de seu compromisso narrativo: "sedução pela palavra escrita. É a capacidade de envolver o leitor, fazê-lo virar a página, emocioná-lo, transformá-lo.” (PENA, 2012, p. 11). Relaciona ainda a frase de Oswald de Andrade sobre o biscoito fino e a massa com aquela presumidamente pronunciada por Maria Antonieta, taxando a cultura de excludente. E finaliza: "Mas a guilhotina já chegou." (PENA, 2012, p. 12).

$\mathrm{Na}$ defesa de seus argumentos, vale-se de seus conhecimentos da área de sua formação, citando, entre outros, Todorov em defesa de uma maior ligação entre literatura e vida e Émile Faguet quando se refere ironicamente ao público dos "escritores obscuros". O Organizador busca se eximir da responsabilidade da escolha explicando que o que fez foi examinar as obras mais citadas em blogues e redes sociais, salas de aula e grupos de discussão. Importa assinalar que tais redes, a despeito de uma pretensa pluralidade, não eliminam a subjetividade construída entre membros de um grupo ou de vários. Outro critério divulgado seria o de escritos pertencentes a gêneros "tradicionalmente desprezados pela crítica literária, como fantasia, terror, fábula, espionagem, folclore e ficção científica, entre outros.” (p. 14). Mesmo sem discutir os rótulos aí arrolados, já que o próprio autor aponta para a dificuldade da classificação em gêneros, citando o filósofo Platão e linguista Maingueneau, é preciso observar o caráter híbrido da lista que envolve forma e tema, o que fortalece a intenção de se pensar em uma biblioteca como uma locadora de filmes dividida 
em seções ou nas listas de mais vendidos divulgadas em jornais.

A palavra manifesto, já discutida neste texto em relação à obra de Ferréz, volta explicitamente na retomada do "Manifesto silvestre", aí transcrito com 10 itens, como nas tábuas da lei. Interessante evocar o Manifesto "J'accuse", de Zola, para realçar a função do intelectual com sua reflexão em praça pública em defesa de uma causa. No aqui denominado "silvestre", destacam-se a força de sedução da palavra, a importância da narrativa, a importância de se atingir um público maior por meio do desprezo pelos academicismos, os jogos de linguagem e os experimentalismos. Além disso, postula-se o papel de formar leitores com a divulgação desse tipo de obra mais acessível não sem declarar a rejeição ao maniqueísmo que separa o difícil do fácil, o popular do erudito, "o moderninho do superficial".

Enquanto críticos e intelectuais como Antonio Candido propunham a caminhada rumo à elaboração estética por meio da formação de um público letrado, o presente movimento busca fazer o caminho inverso ou, pelo menos, com uma proposta diversa na medida em que se quer alcançar o leitor dado como desprezado através do texto mais fácil e acessível. Paradoxalmente, o texto que vem a seguir no alegórico item "A invenção do cânone" é pleno de referências atinentes a um público bem aquinhoado e seus gostos requintados. É claro que se trata de uma ironia aos mecanismos de eleição dos clássicos feitos justamente por um segmento social elitizado, mas, a quem se dirige tal texto: ao "leitor leigo" que buscaria o livro em questão como leitura fácil ou justamente aos pares que "congelam os autores adorados pelos leitores"? Não haveria na publicação dessa antologia, que quer fazer face à Granta e seus critérios críticos, um legítimo desejo de formação de cânones?

Como Ferréz que separa os leitores entre os que merecem a paz daqueles a quem se declara guerra, no texto da orelha do livro de Felipe Pena afirma-se que "os escritores da Geração subzero colocam a cara na vidraça e esperam pelas pedras e flores. Mais pedras do que flores." O tom é, pois, de guerra, tanto em uma como em outra antologia "marginal".

Não é a guerra uma forma de ganhar terreno, conquistar territórios? Como se viu, diferentes armas são utilizadas para se vencer as batalhas empreendidas. Estratégias mercadológicas ou táticas de penetração em terreno interditado (cf. CERTEAU, 1994) fomentam percursos em cruzamento na conquista da polis, do direito de dizer eu frente ao outro que pode até renegá-lo, mas o constitui. Nessa direção faz-se uma analogia entre as antologias e a cidade vista como grandes, intensas e heterogêneas constelações de trajetórias, a exigir uma negociação complexa entre indivíduos e grupos (Cf. Massey, 2008, p. 226).
Nesse sentido, vale recorrer ao sentido de ética da alteridade como proposta por Lévinas a partir da concepção de que o eu só se constroi em relação a um outro que o interpela. O filósofo questiona a possibilidade de se classificar o outro, categorizando-o, o que seria sempre uma violência contra ele. Para o autor,

a alteridade não é uma mera categoria abstrata para pensar de forma universal bons conselhos éticos. A questão ética perde todo seu caráter formal quando meu modo de vida se pauta pela interpelação do outro. O rosto do outro interpela sempre. Ele é um apelo permanente para reconsiderar meu modo de ser e viver. (RUIZ, 2008, p. 145)

Marginal ou consagrada, periférica ou central, a produção literária compõe, mais que antologias, constelações móveis, marcadas pela busca da qualidade estética, pela luta política, pelos direitos éticos. Nessas constelações pode-se perscrutar a "Sobrevivência dos signos ou das imagens, quando a sobrevivência dos próprios protagonistas se encontra comprometida." (DIDI-HUBERMAN, 2011, p. 150).

\section{Referências}

ARENDT, Hannah. A condição humana. Trad. Roberto Raposo. Rio de Janeiro: Forense Universitária, 2005.

BENTES, Ivana. Da estética à cosmética da fome. Jornal do Brasil. Rio de Janeiro, 08 jul. 2001. Caderno B, p. 1-4.

CANDIDO, Antonio. Literatura e subdesenvolvimento. In: MORENO, César Fernández (Org.). América latina em sua literatura. São Paulo: Perspectiva, 1979. p. 343-362.

CANDIDO, Antonio. Literatura e subdesenvolvimento. In: Educação pela noite e outros ensaios. São Paulo: Ática, 1987.

CANDIDO, Antonio. Formação da literatura brasileira. Belo Horizonte: Itatiaia, 1981.

CANDIDO, Antonio. Literatura e sociedade. São Paulo: Nacional, 1976.

DELEUZE, Gilles; GUATARI, Felix. Kafka, por uma literatura menor. Tradução Júlio Castañon Guimarães. Rio de Janeiro: Imago, 1977.

DIDI-HUBERMAN, Georges. Sobrevivência dos vaga-lumes. Tradução: Vera Casa Nova e Márcia Arbex. Belo Horizonte: Editora da UFMG, 2011.

FERRÉZ (Org.). Literatura marginal: talentos da escrita periférica. Rio de Janeiro: Agir, 2005.

FISCHER, Luís Augusto. Letras em números: o que as estatísticas dozem sobre "Granta". Folha de S. Paulo, 2 set. 2012. Ilustríssima, p. 6-7.

GRANTA, 9: os melhores jovens escritores brasileiros. Rio de Janeiro: Alfaguara, 2012.

MASSEY, Doreen. Pelo espaço: uma nova política da espacialidade. Tradução Hilda Pareto Maciel e Rogério Haesbaert. Rio de Janeiro: Bertrand Brasil, 2008. 
OLIVEIRA, Nelson de. Geração 90: manuscritos de computador. São Paulo: Boitempo, 2001.

OLIVEIRA, Nelson de. Geração 90: os transgressores. São Paulo: Boitempo, 2003.

OLIVEIRA, Nelson de. Geração zero, zero: fricções em rede. Rio de Janeiro: Língua geral, 2011.

OS ELEITOS. Folha de S. Paulo, 16 jul. 2012. Ilustrada, p. 1. PENA, Felipe (Org.). Geração subzero: 20 autores congelados pela crítica mas adorados pelos leitores. São Paulo: Record, 2012.

ROCHA, Glauber. A estética da fome. Revista Civilização Brasileira, n. 3, jul. 1965.
RUIZ, Castor B. Emanuel Levinas, alteridade \& alteridades - questões da modernidade e a modernidade em questão. In: SOUZA, Ricardo Timm de et al. (Org.). Alteridade e ética: obra comemorativa dos 100 anos de nascimento de Emmanuel Levinas. Porto Alegre: EDIUCRS, 2008. p. 117-148.

SANTIAGO, Silviano. O cosmopolitismo do pobre. Belo Horizonte: Ed. da UFMG, 2004.

Recebido: 30 de abril de 2014

Aprovado: 06 de junho de 2014

Contato: iwalty2@yahoo.com.br 